Review Article

\title{
A COMPREHENSIVE REVIEW ON COMPARISON OF GDOCP IN PHARMACEUTICAL MANUFACTURING UNIT AS PER EUROPEAN AND WHO GUIDELINES
}

\author{
MALE TEJASWI ${ }^{2}$, VINOD KUMAR K. ${ }^{{ }^{*}}$, CHITHRA SHEKAR C. ${ }^{1}$, SRIKANTH K. ${ }^{3}$ \\ 1,2,3Department of Pharmaceutical Analysis, Raghavendra Institute of Pharmaceutical Education and Research (RIPER)-Autonomous, \\ Ananthapuramu 515001, AP, India, ${ }^{2}$ Department of Pharmaceutical Quality Assurance, Raghavendra Institute of Pharmaceutical \\ Education and Research (RIPER)-Autonomous, Ananthapuramu 515001, AP, India \\ ${ }^{*}$ Email: ripervinod@gmail.com
}

Received: 04 May 2021, Revised and Accepted: 26 Jun 2021

\begin{abstract}
To review the good documentation practices in the pharmaceutical industry as per the guidelines provided in the European Commission and WHO (World Health Organisation). GDocP is a systematic method of planning, evaluating, approving, issuing, documenting, preserving, and archiving records. GDocP is a must when operating in an atmosphere of existing GMP. To provide an overview of good documentation practices for those employed in the pharmaceutical and healthcare sectors. The GDocP stands for good documentation practice which can be described as an integral part of quality assurance $(\mathrm{QA})$ and thus related to all aspects of GMP. There are very few articles related to the comparison of GDocP in the pharmaceutical manufacturing unit as per European and WHO guidelines hence we are trying to develop a study on the comparison of GDocP guidelines. Public and private organizations, institutions, and regulatory authorities working and cooperating and with the pharmaceutical industry are involved at the international and national level to reach a consensus on the guidelines and laws for the production of medicinal products for human. This article explains how these participants work and cooperate and set out current regulations along the lines of the European community and WHO referencing, where appropriate, the practiced guidelines, outside space regulatory action referred to above. In this way, the goal is to achieve exceptional standards of quality, protection, and efficacy in the manufacture of health products.
\end{abstract}

Keywords: Good documentation practice, European union, World health organisation, Regulatory authorities

(C) 2021 The Authors. Published by Innovare Academic Sciences Pvt Ltd. This is an open access article under the CC BY license (https://creativecommons.org/licenses/by/4.0/) DOI: https://dx.doi.org/10.22159/ijcpr.2021v13i4.42736 Journal homepage: https://innovareacademics.in/journals/index.php/ijcpr

\section{INTRODUCTION}

GdocP stands for Good Documentation Practices which is defined as a systematic process for planning, evaluating, approving, preserving, issuing, documenting, and archiving records. Good documentation Practices (GdocP) should not be confused with Good Distribution Practices (GDP). Documentation activities should now be referred to as GdocP (not GDP), but both documentation and distribution practices have not stopped using the term GDP for many publications. Double definitions will increase the QMS problems for the acronym GDP; so, make sure you have clear GdocP for Good Documentation Practices. Good documentation is an important part of the framework for quality Assurance and is essential for operating following GMP requirements. The distinction between GdocP and GMP is that GMP includes drug production and GdocP is reporting the results of GMP outcomes [1]. Data integrity is a part of GdocP and GdocP is a part of GMP. In the manufacturer's QMS, the different types of documents and media used should be fully specified. Documentation may present in different forms, which include paper-based, photographic media, or electronic. Good record keeping is not only allowing to comply with industry standards and legal requirements for safety, effectiveness, and product quality during regulatory reviews (GMP audits), but also it is necessary to ensure your documentation activities and your goods. GdocP aims to ensure that record-keeping and reporting are met by internationally agreed standards [2]. Written documents eliminate mistakes in different pharmaceutical practices and each operation is written in particular documents such as sops and strictly followed. Spoken interactions may create errors hence all essential records like Master Formula Record procedures and records should be free of errors and recorded [3]. Documentation offers the route for auditors to determine the overall efficiency of activities within an organization and the end product. In the European Union, eudralex is the set of rules and regulations regulating medicinal products. Guidelines for the interpretation of the principles and guidelines of GMP for medicinal products for human and veterinary use set out in commission directive 2003/94/EC and 91/412/EEC respectively, shall be included in the rules regulating medicinal products in the European
Union. GMP guidance for pharmaceuticals is issued by the WHO. These instructions are followed across the world. The WHO guidelines are referred to as WHO TRS (Technical Report series). WHO-TRS 986 Annex 2 provides guidance for GMP for pharmaceutical products $[4,5]$.

\section{Importance of GdocP}

As per the control of GMP documentation, "unless it is written down, it has not taken place". Information on where, why, who, how, and when to fulfil the assignment is given in the documents [6]. The paper contains proof that the assignments have been done as they are meant to be. The ISO sets standard specifications for the quality system used in GDocP. To obtain ISO 9001-2015 certification and other industry-specific ISO certifications, GDocP is necessary.

\section{Basic requirements for $\mathrm{GdocP}$}

Every time document the entries simultaneously at the moment of operation. Often record the signature, date in the GMP records. For documenting information in GMP documents every time make use of an ineradicable ballpoint pen. Enter the data in the language of english into the GMP records. To complete the GMP documents, avoid the usage of a pencil or a removable or water-soluble ink pen. Never sign any forms for anyone else. Only sign up for the job you have done yourself. Never backdate records with GMP. Never discard any kind of original raw data. To record the details, avoid usage of scratch papers, loose papers, or "post-it". Unless the expiry of the retention period is reached, never discard any GMP. Records. The basic requirements of GDocP must be fulfilled by documents and records used in the production operation, along with supporting processes.

\section{DISCUSSION}

\section{GdocP in pharmaceutical manufacturing unit}

All documentation entries must be rendered in handwriting which is clear and legible with indelible black ink. Document verification made by QA with the aid of indelible blue ink. Green ink is only used 
for issuing the BMR/BPR by QA. Do not leave any columns unfilled in the records or document. Write "N. A" whenever any column in the document is not applicable. Write nil or place '-----' if there are no comments. Time should be represented as HH. MM, i.e., $4 \mathrm{pm}$ as $16.00 \mathrm{~h}$. The date must be represented as DD-MM-YY or DD. MM. YY or DD/MM/YY during the issuance of documents and in other record books. The date must be represented as DD-MM-YYYY or DD. MM. YYYY or DD/MM/YYYY while approving the documents. Draw a line over the page from the top left to the bottom right of the page if any page(s) is left blank and write "CANCELLED" or "N. A" (Not Applicable) over the page and sign with the date. QA counter signature is needed if the whole page or paragraph has to be cancelled from a document. Not permitted for the usage of pencil entries and correction fluid. All personnel must prevent errors during the entry of data. If any entry error occurs, the error should be corrected as indicated below. Do not overwrite incorrect entries Cross out with a line that permits the original entry to be read Write down the accurate entry close by the cross out. Sign and put the data on which the correction was made. The reasons for the correction shall be registered where necessary. Whenever the correction has been made on a date later than the original date of entry, it shall be rectified as stated above along with the date and countersignature of the supervisor or QA. The following steps should be taken if a full line or paragraph or page is to be removed from a sequential record (e. g. logbook or stock card) Cross out with a line, write a comment detailing the reason for cross out deletion, Sign and position the date on which the correction was made.

\section{European guidelines on GdocP}

EU GMP Chapter 4 provides guidelines for GDocP. Good Documentation is an integral part of the QA system and is necessary for operating following GMP requirements [7]. To monitor and record GMP enforcement there are two main forms of documents used: 1 Instructions (directions, requirements), 2 Records or Reports. The implementation of an instruction results in the production of records or reports as shown in fig. 1. Beneath both Instructions and Records or Reports, types of documents are described in more detail. It is the presence of correct and reliable reports that prove that standards have been followed, and therefore the work complies with GMP regulations.

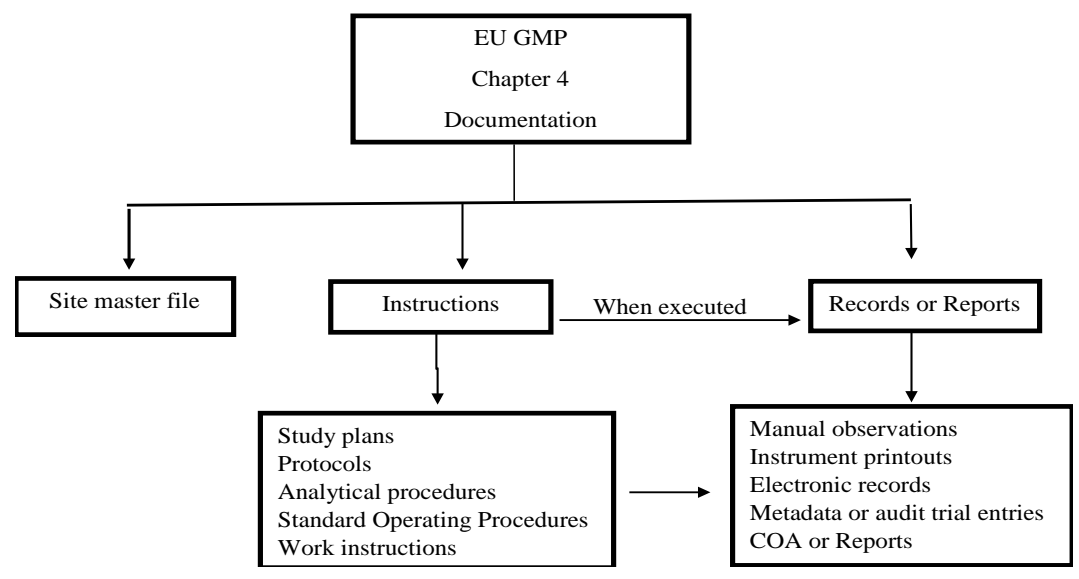

Fig. 1: Principles of GDocP from EU GMP

\section{Required GMP documentation}

\section{Instructions (directions or requirements)}

Specifications: Describe in depth the demands to be met by the goods or materials used or acquired during development [8]. They serve as a foundation for assessing efficiency, Manufacturing Formulae, Processing, Packaging, and testing Instructions: Present descriptions of all primary materials, equipment, and electronic systems to be used andprovide all instructions for processing, packing, sampling, and analysis. Where appropriate, the process controls and analytical process technologies to be used should be defined along with acceptance requirements. Procedures: Include guidance for such operations to be performed, Protocols: Guide certain discrete operations to be performed and registered, Technical Agreements: Contract suppliers and acceptors for outsourced operations are decided upon.

\section{Record/Report type}

Records: Provide proof of different actions taken to show compliance with the instructions e. g. events, accidents, inquiries, and in case of produced lots, history including the delivery of every batch of goods, Certificate of Analysis: Provide a review of the test results for samples of goods or materials along with a compliance assessment of the prescribed standards, Reports: Record the conduct of specific exercises, initiatives, or inquiries along with findings, conclusions, and suggestions.

Basic requirements for GdocP for any quality system as per chapter 4(8)

Say what you do: Have an instruction to report a routine task such as a process of study or an SOP, Do what you say: Follow the guidelines and register them if there are any deviations from the protocol, Document it: Produce a record to indicate that the instructions have been followed. A segment called "Good Documentation Practices" which includes clauses 4.7-4.9 as shown in table 1 is also included in chapter 4 . As per this, the specifications are surprisingly short and brief and each controlled entity and laboratory need to interpret them [8]. The regulatory specifications in table 1 are generally based on paper and the computerized system is not explicitly stated, as the relevant regulations are set out in EU GMP Annex11. In chapter 4 there are other segments on the generation and control of documentation (clauses 4.1-4.6), retention of documents (clauses 4.10-4.12), and the types of documents required (clauses 4.13-4.32). Given that GDocP is the subject of this study, we may see that there are not many "Attributable, Legible, Contemporaneous, Original, Accurate (ALCOA) concepts are shown in table 1. Clause 4.7 is equivalent to legible, 4.8 is Contemporaneous and 4.9 is partly accurate. We might say that chapter 4 doesnot adhere to the principles of ALCOA, this is why together with Annex 11 chapter 4 is being revised to reinforce the criteria for data integrity [9].

\section{WHO guidelines on GdocP}

Documentation is an important component of the Quality Assurance framework, and it should be present for all aspects of GMP [10]. The objectives of GDocP are to identify the standards and procedures for all products and manufacturing and control methods; to ensure that all manufacturing staff know what to do and when to do it; to ensure that approved persons have all the details they need to determine whether or not to release a batch of medication for sale; and to ensure the presence of recorded evidence, traceability, and the provision of records and an audit trail that will allow for further investigation, it ensures that the data necessary for validation, evaluation, and statistical analysis is accessible. 
Table 1: EU GMP chapter 4 requirements for good documentation practices

\begin{tabular}{ll}
\hline Clauses & Good documentation practices \\
\hline 4.7 & $\begin{array}{l}\text { Handwritten submissions must be built-in clear, legible, ineradicable way. } \\
\text { Records must be drawn up or finished at the moment of each operation and in this way that all-important activities relating to the } \\
\text { manufacture of medicinal products are detectable. }\end{array}$ \\
$\begin{array}{l}\text { Any modification made to the entry of a document must be signed and dated; the modification should make it possible to read the } \\
\text { original material. The reason for the modification should be registered, where necessary. }\end{array}$ \\
\hline
\end{tabular}

\section{General guidelines}

Documents should be carefully planned, written, examined and disseminated. They must stick to the specific sections of the manufacturing and marketing permits. The required responsible persons should authorise, sign, and date the documents. Without authorisation and consent, no document should be updated. The contents of documents should be clear; the title, meaning and intent should all be specified. They should be set out in a logical way and easy to understand. Documents that are reproduced should be clear and legible. Working documents must not be copied from master documents if any mistakes are introduced during the reproduction process. Documents should be checked and revised on a regular basis. When atext is updated, a mechanism should be in place to avoid the use of the superseded edition by mistake. Documents that have been superseded should be kept for a fixed amount of time. When data inserted into records, it must be done in a simple, legible and indelible manner. Enough room should be set aside for such entries. Any revisions to a document should be signed and dated, and the changes should be made in such a way that the original information can be read. The reason for the move should be reported if necessary. When any action is taken, documents should be maintained or completed in such a way that all significant activities related to the manufacture of pharmaceutical products can be tracked. Records should be held for at least one year after the finished products expiration date. Electronic data processing systems, as well as photographic or other accurate methods, may be used to record data (and records for storage). The quality of the records should be reviewed, and other master formulae and comprehensive SOPs relating to the method in use should be available. Only approved people should be able to enter or alter data in the computer system, and there should be a record of changes and deletions; access should be limited by passwords or other means, and sensitive data should be entered separately. Back-up transfer on magnetic tape, microfilm, electronic discs, paper printouts, or other means should be used to secure batch records stored electronically. It's vital that the data is usable during the retention phase.

\section{Comparison of European and WHO GDocP principles ALCOA and ALCOA+principles}

As an acronym for five data quality standards, ALCOA was used for data integrity. The European Medicines Agency has applied four additional requirements to the GCP guidelines on electronic source data and has named it ALCOA+. The WHO guidance is the one that provides the most extensive discussion of ALCOA and GDocP for both paper and electronic records (table 2).

Table 2: Comparison of european and WHO GDocP principles

\begin{tabular}{|c|c|}
\hline European guidelines & WHO guidelines \\
\hline ALCOA+principles: & ALCOA principles: \\
\hline Attributable: Who and when received the data or conducted an action? & Attributable: Information is recorded in the database such that the \\
\hline Legible: Can the entry or data be read and understood? & originator of the data (e. g. an individual or a computer system) \\
\hline Contemporaneous: At the moment of operation, is the work & uniquely recognizes it as executed. \\
\hline documented? & Legible, traceable and permanent: These terms apply to the criteria \\
\hline Original: Is there a printout or a verified copy of it or an observation? & that documents be readable, easy to understand, and allow the clear \\
\hline Accurate: Without recorded amendments, are there no errors or editing? & image of the sequencing of the steps or events in the database such that \\
\hline $\begin{array}{l}\text { Complete: Is all the information available, containing any replication or } \\
\text { reanalysis carried out on the sample? }\end{array}$ & $\begin{array}{l}\text { all GxP activities carried out can be completely reconstructed at any } \\
\text { point during the preservation period of records set by the relevant GxP }\end{array}$ \\
\hline Consistent: Are all elements of a chromatographic analysis carried out & by the individuals reviewing these records. \\
\hline $\begin{array}{l}\text { similarly over time, as the series of events that follow on and the dates or } \\
\text { timestamps in the expected sequence, especially to be fair or precise? }\end{array}$ & $\begin{array}{l}\text { Contemporaneous: The data collected at the time of generation or } \\
\text { observation. }\end{array}$ \\
\hline $\begin{array}{l}\text { Enduring: Is all data recorded in official media (either on paper or in a } \\
\text { computerized system) and not on the backs of envelopes, packets of } \\
\text { cigarettes, post-it notes, body parts, or laboratory coat sleeves? }\end{array}$ & $\begin{array}{l}\text { Original: First or source data or the information collection and all } \\
\text { subsequent data needed to completely recreate the output of the GxP } \\
\text { process. }\end{array}$ \\
\hline $\begin{array}{l}\text { Available: Are all the details easily collected over the lifespan of the } \\
\text { record for analysis, audit, or inspection?. }\end{array}$ & $\begin{array}{l}\text { Accurate: The word "Accurate" implies that the information is correct, } \\
\text { factual, complete, legitimate, and reliable. }\end{array}$ \\
\hline
\end{tabular}

\section{CONCLUSION}

This study has provided an overview of GDocP principles given in the European and WHO guidelines. GDocP is an essential element of GMP compliance. GDocP has been addressed from the EU GMP chapter 4 regulations and WHO data integrity guidelines. Both have very good guidance and explanation for both paper and electronic systems of the ALCOA principles. The ALCOA and other attributes as defined by the regulatory authorities and the GCP should be demonstrated by documentation. Similar specifications to the WHO GMP are imposed by the EU GMP. A crucial prerequisite for maintaining data integrity is knowing GDocP before calls from an investigator. When comparing the criteria of the WHO and the European GMP, it can be noted that both standards have been matched very clearly in the last few years. All chapters reviewed are based on international standards, such as PIC/S or ICH guidelines. In its application and clarification, the WHO guidelines are partly more elaborate and provide the consumer with additional details about how the guidelines ought to be understood and what needs to be taken care of.

\section{ACKNOWLEDGEMENT}

Authors are extremely thankful to Raghavendra Institute of Pharmaceutical Education and Research (RIPER) management, Anantapur for their support.

\section{ABBREVIATION}

ALCOA: Attributable, Legible, Contemporaneous, Original, Accurate, EU: European Union, GxP: Good...Practice, GdocP: Good Documentation Practices, GMP: Good Manufacturing Practices, GDP: Good Distribution Practices, GCP: Good Clinical Practices, ICH: 
International Council for Harmonisation of Technical Requirements for Pharmaceuticals for Human use, PIC/: Pharmaceutical Inspection Co-operation Scheme, Q: Quality Assurance, SOP: Standard Operating Procedure, WHO: World Health Organisation.

\section{FUNDING}

Nil

\section{AUTHORS CONTRIBUTIONS}

All the authors have contributed equally.

\section{CONFLICT OF INTERESTS}

The authors declare no conflict of interest, financial or otherwise

\section{REFERENCES}

1. Sandle T. Good documentation practices. J Valid Tech; 2014.

2. Bargaje C. Good documentation practice in clinical research. Perspectives Clin Res 2011;2:59.

3. Naidu RP. Causality assessment: a brief insight into practices in pharmaceutical industry. Perspectives Clin Res 2013;4:233.
4. Kumar K. Good documentation practices (GDPs) in pharmaceutical industry. J Anal Pharm Res 2017;4:00100.

5. Patel KT, Chotai NP. Documentation and records harmonized GMP requirements. J Young Pharma 2011;3:138-50.

6. Tairova KE, Dilbarkhanova JR, Rayisyan MG, Sekerin VD, Evgenievna A. Aspects of improving the regulatory system of pharmaceutical products in the republic of Kazakhstan. J Adv Pharm Edu Res 2020;10:87-92.

7. Patel LJ, Panjwani KR, Ray J. Review on good documentation practice in pharmaceutical manufacturing unit as per European Union GMP chapter-4 on documentation. Pharma Tutor 2019;7:1-4

8. Patel KT, Chotai NP. Documentation and records: harmonized GMP requirements. J Young Pharm 2011;3:138-50.

9. McDowall RD. Data integrity and data governance: practical implementation in regulated laboratories. Royal Soc Chem 2018. https://doi.org/10.1039/9781788013277

10. WHO Expert Committee on Specifications for Pharmaceutical Preparations. Meeting, World Health Organization. WHO Expert Committee on Specifications for Pharmaceutical Preparations: Fiftieth Report. WHO; 2016. 